\title{
ARTICLE
}

\section{Assessment of organizational management capability and employee' satisfaction at select maternity hospitals in Ulaanbaatar}

\author{
Batbold Tseleejav1, Tumurbaatar Luvsansambuu² and Munkh-Erdene Luvsan ${ }^{3 *}$ \\ ${ }^{1}$ Section of Administration, Amgalan Maternal Hospital, Ulaanbaatar, Mongolia \\ ${ }^{2}$ Sector of Administration, Planning, monitoring and evaluation, Capital City Health Department, \\ Ulaanbaatar, Mongolia \\ ${ }^{3}$ Department of Health Policy, School of Public Health, Mongolian National University of Medical Sciences, \\ Ulaanbaatar, Mongolia
}

ARTICLE INFO: Received: 22 Apr, 2020; Accepted: 03 Dec, 2020

\begin{abstract}
Healthcare organizations are implementing quality management system by forming legal entity, by carrying out administrative structural changes and developing healthcare organization's structure, set-up, functional standards, clinical guideline, rules and employee' moral principles. Introduction of accreditation system into healthcare organizations is becoming an accepted standard, however, healthcare paradigm shift outcome is insufficient. In this connection, researchers, citizens and policy makers are speaking out that the quality of and access to healthcare service is getting worse than before. Management capability index presents management assessment by score, assesses outcome of organizational functions and makes it possible to measure management capability. This study was performed at the Amgalan maternity hospital, Urguu maternity hospital and Khuree maternity hospital between July 2019 and September 2019 and cross-sectional study method was used. The study involved 480 employees of above-mentioned hospitals. We used 9 chapter and 90 criteria that were used in more than 30 Mongolian Public (i.e., Governmental) Organizations for capability assessment to determine management capability index of the maternity hospitals. Organization management capabilities, as an organizational goal and task, leadership skill in an organization, appropriate structure and set-up, organization's incentive and motivation leverage schemes, organization's relationship and collaboration, organizational behavior and culture, resource utilization, knowledge and innovation, organizational productivity, quality and performance were included in the questionnaire. Organizations capability index was calculated with a score point of 1 to 5 for each question. A total 480 employees, including 220 from the Urguu maternity Hospital, 125 from the Khuree maternity hospital and 135 from the Amgalan maternity hospital were included in this study. When responses to the question of management capability were according to duties and functions, not much difference was observed among the three hospitals, but when the responses were compared with that provided by doctors, nurses, obstetricians and other medical staff, a 1.8 percentage higher point was given by the administrative and service staff.
\end{abstract}

*corresponding author: munkherdene@mnums.edu.mn

https://orcid.org/0000-0001-7819-1765

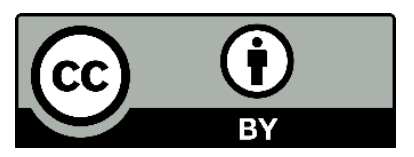

The Author(s). 2020 Open access This article is distributed under the terms of the Creative Commons Attribution 4.0 International License (https://creativecommons.org/licenses/by/4.0/), which permits unrestricted use, distribution, and reproduction in any medium, provided you give appropriate credit to the original author(s) and the source, provide a link to the Creative Commons license, and indicate if changes were made. 
Regression analysis showed strong relation between management capability assessment of doctors, nurses, obstetricians and other employee of the select hospitals $(p<0.001$ and $R=0.89)$. Organizational management capabilities of Urguu and Khuree Maternity Hospitals, which have not yet introduced quality management system, are different from the Amgalan maternity hospital's organizational management capability $(p=.000)$. Doctors, obstetricians, nurses and other employee' assessed organizational management capability by 73.5 percent respectively. There is a positive correlation ship between organizational capability and employee satisfaction. Better and higher management capability of an organization results in higher employee satisfaction.

Keywords: Organizational management capability; management; quality; performance;

\section{INTRODUCTION}

Organizational management capability gives the possibility to analyse whether the given organization's goals and vision are clearly defined, and also to determine the effectiveness of the accomplished goals and projects implemented. In other words, an organization is an entity compromising of multiple people, and organizational management capability is expressed by equal distribution of resources and entity optimality [1]. An organization's must develop and make progress by making changes associated with community, policy and internal and external resources. Proper organizational management and system can lead to such a development [2]. Quality management system and ISO 9001 are central in implementing the goals of developing an organization's management reform, ensuring equal resource distribution, improving product or service quality, trade and manufacture, providing operational safety and improving competency [3]. Therefore, ISO 9001 and the concept of quality management and confirmation, especially in health care organization, are improving [4]. Incorporation of accreditation system in healthcare is becoming an important stage in verifying standard application. However, effort to change healthcare to be in sync with the new and changing community environment is having little impact, if any, and international researchers, citizens and policy makers have been critical about the decline in the key healthcare indicators, including healthcare quality, and allocations compared with the previous levels. An alternative indicator to assess organizational management capability is employee satisfaction, which is primarily determined by the size of remuneration, incentives, promotion, the type of job, management and co-workers, which can impact the participation of the organization. Many researchers have determined that employee satisfaction is only expressed by their feelings [5]. In the $21^{\text {st }}$ century, organization executives are starting to focus on their employee' satisfaction. Personal income and workplace relationships proved to be positively related to all the three indicators of job satisfaction [6]. All organizations need to motivate and appreciate their employee's work. This can strongly influence their satisfaction at workplace. However, studies have shown an in decrease of employee' satisfaction and enthusiasm to work but an increase in cases of employee' leaving their workplace [7]. Healthcare employee' and doctor's satisfaction of work can influence patients, alongside their work and profession [8]. In China, healthcare system management has undergone deep changes and at the same time, citizen's health knowledge and concepts have improved. So, demand for higher quality healthcare has increased [9]. According to China's Health Industry $4^{\text {th }}$ report, 48.51 percent of hospital employee' reported that they do not get satisfaction from their current job, while 95.66 percent of hospital employee' and doctors, who were involved the study, were critical about the level of income and employee satisfaction with their jobs [10]. In many countries, there are insufficient scientific articles about healthcare 
specialist's satisfaction and there is a lack of attention to this matter [11]. There are many factors that influence employee' satisfaction, such as working environment, policies and procedures, intention, goals, social safety net and management etc. Factors influencing job satisfaction can be theoretically divided into 5 categories: salaries and wages, personality job fit, occupation satisfaction, motivation, possibility of learning new things, organizational management, impact of leader's skill, and organization culture [12]. Danish Happy Research Institute showed that 71 percent of total employee' have responded that the following 6 factors primarily affect job satisfaction: Purpose (42\%), management (20\%), influence $(13 \%)$, achievements $(10 \%)$, work/life balance $(14 \%)$ and team mates $(1 \%)$ [13]. During the last several years, Mongolian maternal and child healthcare organizations

\section{MATERIALS AND METHODS}

This study was conducted at the Amgalan Maternity Hospital, Urguu Maternity Hospital and Khuree Maternity Hospital July to September 2019 by using a cross-sectional study method. The study mobilized a total of 480 employees from these three hospitals. We used Chapter 9 with 90 criteria of assessing organizational management capability, which are used by more than 30 public organizations of the country, in order to determine organizational management capability index of maternity hospitals. These 90 criteria were included in the 90-question questionnaire, such as organizational goals and tasks, leadership skill in an organization, appropriate organizational structure and set-up, organization's motivation and leverage, organization's relationship and collaboration,

\section{RESULTS AND DISCUSSION}

The study mobilized a total of 480 employees, including 220 employees from the Urguu Maternity Hospital, 125 from Khuree Maternity Hospital and 135 from the Amgalan Maternity Hospital. These included 46 have been making efforts to increase maternal and child healthcare delivery and decrease maternal and child mortality rates. The importance of allocation of resources for the purpose cannot be underestimated.

Proceeding from this premise, there is a need and a requirement to assess and evaluate leadership management performance (and/or operation) of maternity hospitals. This study aimed to compare organizational management capability of maternity hospitals that have implemented quality management system and those who have not. The objectives of our study focused on the following. One, determine the ranking of maternal hospitals providing maternal and child care two, to study organizational management capability of maternal hospitals, and third, to assess and evaluate employee' satisfaction.

organizational behavior and culture, resource utilization, knowledge and innovation, organizational productivity, quality and performance. Each question was assessed by a score of 1 to 5 and the organizations capability index was estimated by assessing each question from 1 to 5 score. Therefore, we used hospital employee' satisfaction questionnaire developed by Minnesota University team to assess employee' satisfaction and estimate mean scores by percent. Statistical Package for Social Sciences (SPSS)-25.0 and Microsoft Excel2018 were used to analyze the data and present the tables and charts, respectively. Student $t$ test was used to determine group difference and quantitative and $\mathrm{p}<0.05$ was interpreted as statistical significance difference.

administration officials, 75 doctors, 208 nurses and midwives, 105 caregivers and service assistants and 46 financial officers. Table 1 shows general information of study participants. 
Table 1. Study participant's general information

\begin{tabular}{lcc}
\hline Variables & Frequency (percent) & p value \\
\hline Gender & & \\
Male & $62(12.9)$ & .416 \\
Female & $418(87.1)$ & \\
\hline Age range & & .380 \\
18-25 & $69(14.4)$ & \\
$26-35$ & $185(38.5)$ & \\
$36-45$ & $113(23.5)$ & \\
46< & $113(23.5)$ & .313 \\
\hline Educational level & $115(24.0)$ & \\
Secondary education & $52(10.8)$ & \\
Tertiary education & $74(15.4)$ & \\
Diploma & $200(41.7)$ & \\
Bachelor & $36(7.5)$ & \\
Masters & $3(0.6)$ & \\
Doctorate & & \\
\hline Occupation & $46(9.5)$ & \\
Administration officials & $75(15.6)$ & \\
Doctor & $208(43.3)$ & \\
Nurse, midwives & $46(9.5)$ & \\
Financial officers & $105(21.8)$ & \\
Care givers and service assistant & & \\
\hline Years, worked in health sector & $77(16.0)$ & \\
Up to one year & $148(30.8)$ & \\
2-5 & $91(19.0)$ & \\
6-9 & $164(34.2)$ & \\
More than 10 years & & \\
\hline Years, worked in current workplace & $118(24.6)$ & \\
Up to one year & $160(33.3)$ & \\
2-5 years & $92(19.2)$ & \\
6-9 years & $110(22.9)$ & \\
More than 10 years & & \\
\hline
\end{tabular}

Table 1, 87.1 percent of total employees of maternity hospitals were female and 12.9 percent were male. Gender, occupation type and years worked in the health sector and workplace were statistically different among study participants, as compared with age and education level.

Table 2 represents organization management capability by 9 categories.

Table 2. Maternity hospitals' management capability

\begin{tabular}{|c|c|c|c|c|}
\hline Organization management capability indicators & Urguu & Khuree & Amgalan & $\begin{array}{c}\mathbf{p} \\
\text { value }\end{array}$ \\
\hline 1. Organization's mission and objective assessment & 77.1 & 76.6 & 92.7 & \multirow{9}{*}{.000} \\
\hline 2. Organization's leadership skill assessment & 75.2 & 75.2 & 90.6 & \\
\hline 3. $\quad$ Effective organizational structure assessment & 74.2 & 76.3 & 91.0 & \\
\hline 4. Organization's initiative and motivation assessment & 67.7 & 69.7 & 89.7 & \\
\hline $\begin{array}{l}\text { 5. Organization's relationship and cooperation } \\
\text { assessment }\end{array}$ & 70.9 & 72.7 & 90.9 & \\
\hline 6. Organization's culture assessment & 69.8 & 72.8 & 89.0 & \\
\hline 7. Organization's resource allocation assessment & 69.4 & 72.5 & 89.1 & \\
\hline 8. Organization's knowledge and innovation assessment & 70.4 & 71.7 & 88.6 & \\
\hline $\begin{array}{l}\text { 9. Organization's productivity, quality and performance } \\
\text { assessment }\end{array}$ & 71.2 & 75.1 & 91.1 & \\
\hline
\end{tabular}


93.0

Table 2 shows that organization's initiative, motivation, culture, resource allocation, knowledge and innovation were considered as the main indicators that needed improvement at maternity hospitals. In order to improve an organization's activity and process, it may be possible to include the 90 criteria in an organization's strategy and progress plan. The Amgalan maternity hospital had put in place suitable quality management objectives for each department related to the organization's mission and objectives. Also, each employee followed these management standards. This can help assess work performances which previously did not include performance assessment. Standardization of healthcare organization's activities among other maternal hospitals could help ensure equal services for all costumers. The Amgalan maternal hospital took stock of the mistakes and errors made, and has made effort to rectify them. This could definitely play important part in improving the quality of service. Also, close cooperation among all employee' and team culture were established for improving quality management system. The improvement in the quality management system at the Amgalan maternity hospital could be associated with the implementation of ISO 9001 and common international standards.

Table 3 shows maternity hospitals' doctors, nurses, midwives and other employee's work functional management.

Table 3. Organizational management capability (by classification of work function)

\begin{tabular}{|c|c|c|c|}
\hline Organizational management capability indicators & $\begin{array}{l}\text { Doctors, } \\
\text { nurses, } \\
\text { midwives }\end{array}$ & Others & p value \\
\hline 1. Organization's mission and objective assessment & 77.6 & 76.6 & \\
\hline 2. Organization's leadership skill assessment & 76.3 & 76.6 & \\
\hline 3. Effective organizational structure assessment & 75.1 & 75.6 & \\
\hline $\begin{array}{l}\text { 4. Organization's initiative and motivation } \\
\text { assessment }\end{array}$ & 67.0 & 70.1 & .001 \\
\hline $\begin{array}{l}\text { 5. Organization's relationship and cooperation } \\
\text { assessment }\end{array}$ & 70.0 & 72.0 & \\
\hline 6. Organization's culture assessment & 69.9 & 71.3 & \\
\hline 7. Organization's resource allocation assessment & 69.6 & 72.4 & \\
\hline $\begin{array}{l}\text { 8. Organization knowledge and innovation } \\
\text { assessment }\end{array}$ & 68.8 & 73.2 & \\
\hline $\begin{array}{l}\text { 9. Organization's productivity, quality and } \\
\text { performance assessment }\end{array}$ & 71.2 & 73.9 & \\
\hline Mean value & 71.7 & 73.5 & \\
\hline
\end{tabular}

Amgalan maternity hospital's organizational management capability was 14.7-20.1 percent, whereas Urguu and Khuree maternity hospital's organizational management capability was only $0-3.9$ percent. There were no significant differences in the response to organizational management capability questionnaire among 2 groups by dividing work function. Administration officials and service employees gave higher assessment on the questionnaire compared with the doctors, nurses, midwives and other employees. Doctors, nurses and obstetrician's assessment of management capability compared with other employees: were $p<0.001$, $\mathrm{R} 2=0.89$, which prove the existence of strong correlation between them (Table 3). 
Table 4. Maternal hospitals' employee' satisfaction assessment

\begin{tabular}{|c|c|c|c|c|}
\hline \multirow{2}{*}{ Variables } & Urguu & Khuree & Amgalan & \multirow{2}{*}{ Mean } \\
\hline & \multicolumn{3}{|c|}{ Percent } & \\
\hline 1. Very busy during working hours & 77.3 & 79.7 & 81.8 & 79.6 \\
\hline 2. It is possible to work individually at workplace & 82.6 & 84.5 & 90.7 & 85.9 \\
\hline 3. $\quad$ Possible to accomplish multiple tasks & 67.9 & 71.7 & 87.2 & 75.6 \\
\hline 4. $\quad$ Team spirit & 88.4 & 88.0 & 93.4 & 89.9 \\
\hline 5. $\quad$ Leadership attention to employees is good & 72.3 & 75.5 & 87.8 & 78.5 \\
\hline $\begin{array}{l}\text { 6. My suggestions can be considered in decision } \\
\text { making. }\end{array}$ & 65.4 & 72.8 & 83.7 & 74.0 \\
\hline $\begin{array}{l}\text { 7. Don't assign any task that may go against my } \\
\text { opinion }\end{array}$ & 72.0 & 73.0 & 85.4 & 76.8 \\
\hline 8. My workplace is secured & 87.9 & 89.6 & 93.9 & 90.5 \\
\hline 9. Environment to work for others & 88.2 & 89.6 & 93.3 & 90.4 \\
\hline 10. Possible to advice others on how to work & 81.5 & 83.2 & 91.6 & 85.5 \\
\hline $\begin{array}{l}\text { 11. I am given freehand in using my knowledge and } \\
\text { skills to the full with initiative }\end{array}$ & 73.7 & 75.5 & 89.9 & 79.7 \\
\hline $\begin{array}{l}\text { 12. Our organization's policy and plans are based on } \\
\text { practical experience }\end{array}$ & 74.3 & 78.7 & 91.9 & 81.7 \\
\hline $\begin{array}{l}\text { 13. My salary and promotion conform to my work } \\
\text { function. }\end{array}$ & 63.8 & 70.6 & 79.3 & 71.2 \\
\hline 14. Career growth possible & 65.6 & 65.9 & 85.4 & 72.3 \\
\hline $\begin{array}{l}\text { 15. Can review administrative decisions and other } \\
\text { work function assessment }\end{array}$ & 67.5 & 74.1 & 86.6 & 76.0 \\
\hline $\begin{array}{l}\text { 16. Can come up with new ideas and experiment } \\
\text { them at workplace }\end{array}$ & 68.5 & 71.0 & 90.7 & 76.7 \\
\hline 17. Working environment condition is better & 72.4 & 71.5 & 93.4 & 79.1 \\
\hline $\begin{array}{l}\text { 18. Cooperation and relationship between colleagues } \\
\text { are good }\end{array}$ & 79.0 & 82.7 & 90.0 & 83.9 \\
\hline 19. Employee appreciation for good performance & 76.7 & 74.4 & 87.0 & 79.4 \\
\hline 20. I enjoy the work I am doing & 84.1 & 86.1 & 93.4 & 87.9 \\
\hline
\end{tabular}

Table 4, shows an assessment of employee' satisfaction at each of the three maternal hospitals, which can be qualified as follows: Minimum employee satisfaction was observed at Urguu maternity hospital in relation to salary commensurate to work performance, maximum satisfaction was expressed by employees of Amgalan maternity hospital in relation to secure workplace at 93.9 percent.

To conclude, total employee satisfaction level was 77.9 percent. Satisfaction assessment for each maternity hospital was 75.4, 77.9 and 88.8 percent respectively at Urguu, Khuree and Amgalan maternity hospitals. It is clear that the Amgalan maternity hospital's employee satisfaction rate was higher than the other hospitals. Employee' independence, organizational management method and organization culture may have had their impact on this showing /Figure 1/. 


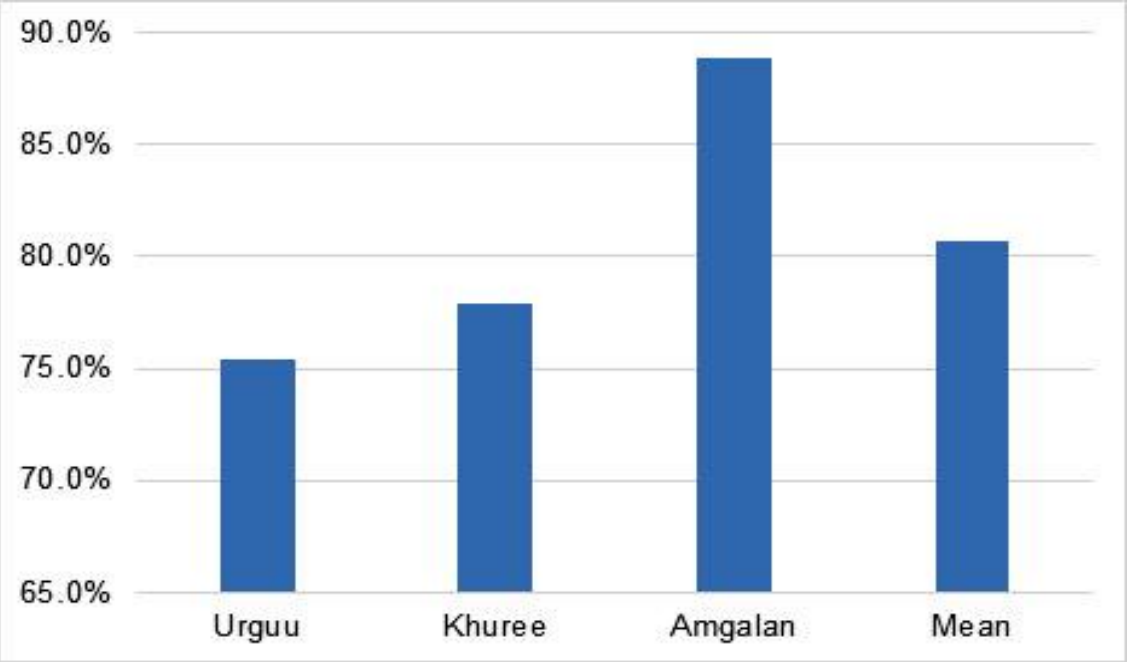

Figure 1. Employee' satisfaction by each hospital

The difference in the work of employee', who participated in the study, and the specific nature of their occupation had certain impact on the satisfaction level. Administration officials and doctors had higher level of satisfaction.
Figure 2 displays employee satisfaction by education level. There is apparently some relationship between education and satisfaction levels.

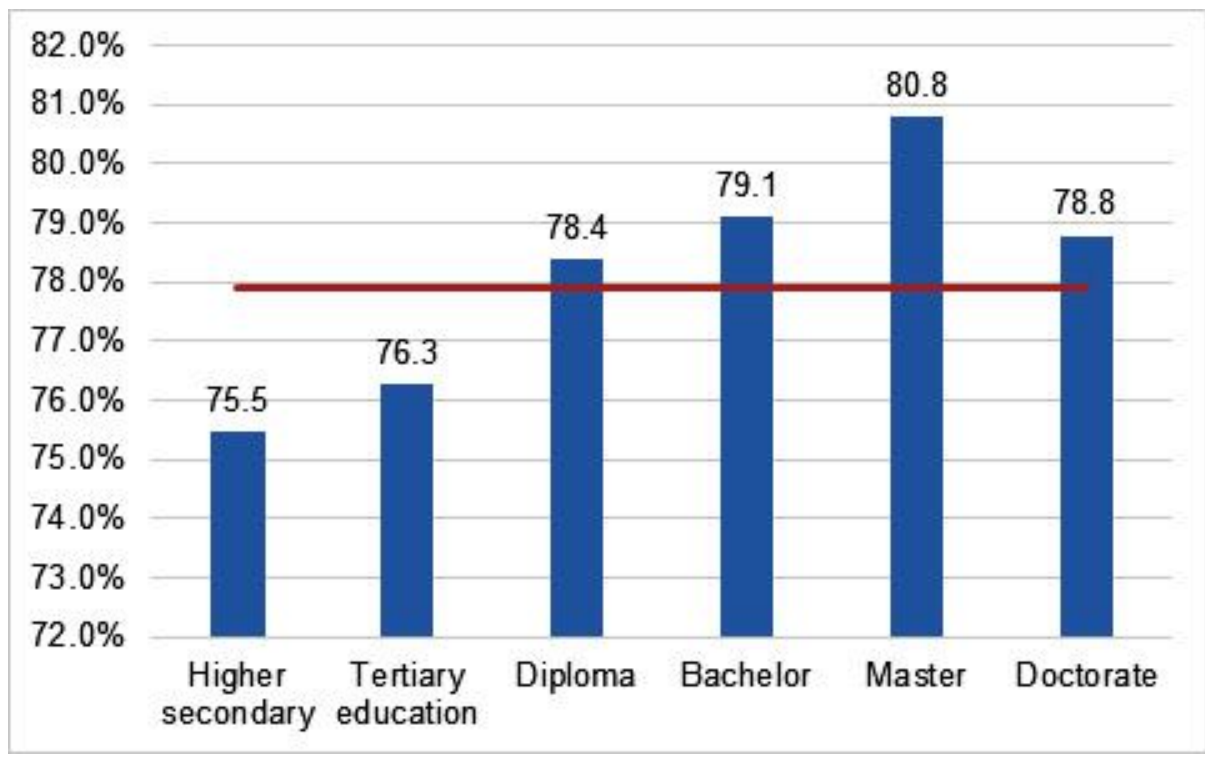

Figure 2. Employee' satisfaction as per education level

Figure 3 shows that employee' who have worked less than 5 years had higher level of satisfaction than others. This obviously reveals that employees who have been working for a long time may not have had enough motivation continue with their job. 


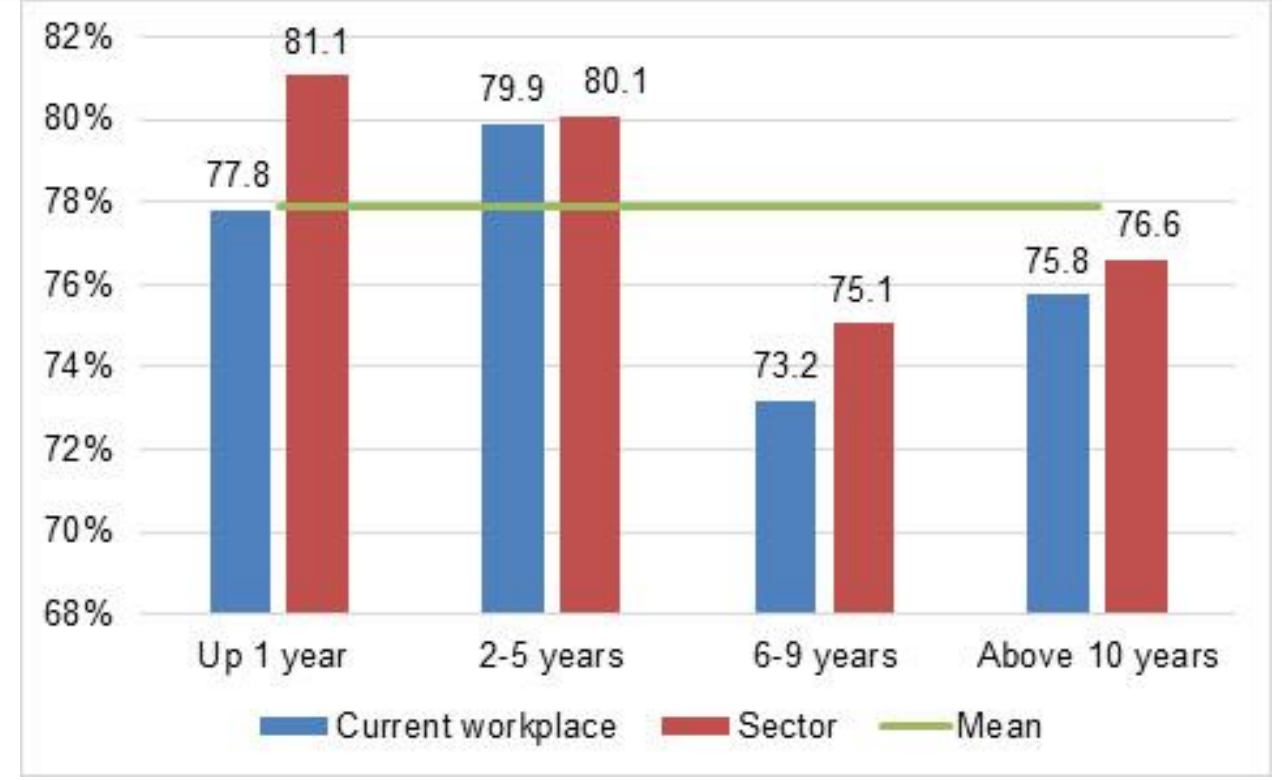

Figure 3. Employee' satisfaction level by years worked

The select organizations have the same financial resource, the type of service they provide are identical, and the organizational structure and set up are no different either. However, the Amgalan maternity hospital was among the three hospitals to implement quality management system, by introducing ISO 9001 standard. This is precisely why, the Amgalan maternity hospital's quality management capability index was 90.31 percent, Urguu Maternity hospital was 71.76 percent and Khuree maternity hospitals was 73.85 percent.

Quality management at Mongolian private and public organizations was higher than 61.4 [1] percent, which was almost at the same rate as the Indian mean quality management capability index at 74 percent. According to a 2012 study, which determined district hospital's management capability, nurse's assessment was 64.4 and doctor's assessment was 76 percent [2]. This means that healthcare organizational management capability had been relatively constant in the last 7 years. Healthcare accreditation program is used internationally for providing and controlling service safety and quality. The health system of Norway has been implementing "Healthcare sector service quality, patient safety and healthcare service without risk" since 2009 [3]. The programme was formally certified in 2015[5]. Lohr KN, Steinwachs DM and Washington University healthcare study showed that quality management system and accreditation implemented at healthcare organizations had resulted in a similar outcome. In other words, it is not possible to compare the above 2 standards but must be seen as mutually complementary. Quality management system enables better norms and standards, higher treatment outcome and productivity, and it also supports stable growth of the organization, its, organizational culture and positive attitudes $[14,15]$.

It has been established that employee satisfaction can be increased voluntarily and without much pressure with the introduction of ISO standards. It is not simple to incorporate organizational culture, infrastructure and cultural beliefs into ISO standard [16-18]. The Norwegian health care system has incorporated ISO 9001 standard as a country specific implementation. According to the hospital staff job satisfaction survey concerning implementation of ISO 9001 standard, regression analysis revealed that there is high job satisfaction among Urguu maternal hospital (75.4 percent), Khuree maternal hospital (77.9 percent) and Amgalan maternal hospital (88.8 percent). This was consistent with another study conducted in the USA by the Human Resource Organization (77-88 percent) $[19,20]$. 


\section{CONCLUSIONS}

There is a significant difference in the organizational management capability and employee satisfaction at Amgalan maternity hospital as compared with Urguu and Khuree

\section{REFERENCES}

1. Unurjargal Ts. "Project Management Guidebook: Work Science-ISO 21500” in 2016, pp.17-36.

2. Gantugs U.District healthcare center's performance assessment. Public health science Doctor's thesis, Ulaanbaatar, 2012, pp.18-76.

3. Institute of Medicine. Improving information services for health services researchers: a report to the National Library of Medicine-Washington, DC: National Academy Press; 1991.

4. Ginsburg PB, Lee PR. Physician Payment. In: Ginzberg Eli., editor. Health Services Research: Key to Health Policy. Cambridge, MA: Harvard University Press; 1991, pp.69-92.

5. Spector, P.E. Job satisfaction: Application, assessment, causes, and consequences. 1997, pp.513-516.

6. Cabelkova, I., Abrham, J., Strielkowski, W. Factors influencing job satisfaction in post-transition economies: The case of the Czech Republic. Int J Occup Saf Ergon. 2015;21(4):pp.448-456.

7. Judge, TA., Weiss, HM., KammeyerMueller JD., Hulin CL4. Job attitudes, job satisfaction, and job affect: A century of continuity and of change. J Appl Psychol. 2017;102(3):pp.356-374.

8. Rui, H. [The influence of doctor - patient relationship and job satisfaction on physicians' organizational citizenship behavior]. Journal of Xi'an Jiaotong University (Social Sciences) 2017;37(4):pp.55-61.

9. Yuan, F., Qian, D., Huang, C., et al. Analysis of awareness of health knowledge among rural residents in maternal hospitals, which are non-ISO hospitals. Employee' satisfaction increased concurrently with higher organizational management capability.

Western China. BMC Public Health. 2015;15(1):pp.1-8.

10. Zihong, M. [Report on the status of doctors' practice in China]. China Health Industry. 2011;(25):pp.12-13.

11. Tingyu W. Quanzhou City No. 1 Hospital doctors' flow management research. Huaqiao University; 2016.

12. Uvsh,P., Kherlen,B and et al. Organization's behavior, 2010,pp.45-51.

13. Happy research institute. Job Satisfaction index. Denmark, 2019.

14. Institute of Medicine. Health services research: training and workforce issues. Washington, DC: National Academy Press; 1995, pp.110-127.

15. Institute of Medicine. Report on health services research-Washington, DC: National Academy Press; 1979, pp.78-98.

16. Lohr, K.N., Steinwachs, D.M. Health services research: an evolving definition of the field. Health Serv Res. 2002;37:pp.15-17.

17. Committee on Quality of Health Care in America. Crossing the quality chasm: a new health system for the 21st century Institute of Medicine- National Academy Press; Washington, DC: 2001, pp.245250.

18. Anell, A., Michael, W. International comparison of health care systems using resource profiles. Bulletin of the World Health Organization. 2000;78:pp.770778.

19. Schoen, C., Osborn, R., Doty, M.M, et al. Toward higher-performance health systems: adults' health care experience in seven countries. Health affairs (Project Hope). 2007;26:pp.717-734. 
20. Committee on Quality of Health Care in America. Crossing the quality chasm: a new health system for the 21st century
Institute of Medicine- National Academy Press; Washington, DC: 2001, pp.140157. 